\title{
Incidence of early and late onset group B streptococcal and Escherichia coli neonatal infection after universal antenatal culture-based screening of group B streptococcus in all public hospitals in Hong Kong: a retrospective cohort study
}

Viola Chan ${ }^{1}$, Shuk Yi Annie Hui ${ }^{2}$, Teresa Ma ${ }^{3}$, C. W. Kong ${ }^{4}$, Lee Ting Kwong ${ }^{5}$, Diana $\mathrm{Chan}^{6}$, Diana Lee ${ }^{7}$, Sau Lan $\mathrm{Mok}^{8}$, Vinci Ma ${ }^{9}$, Yim Chong $\mathrm{Lo}^{9}$, Kwok Yin Leung ${ }^{10}$, and Wing-cheong LEUNG ${ }^{1}$

${ }^{1}$ Kwong Wah Hospital

${ }^{2}$ Prince of Wales Hospital

${ }^{3}$ Queen Elizabeth Hospital

${ }^{4}$ United Christian Hospital

${ }^{5}$ Tuen Mun Hospital

${ }^{6}$ Queen Mary Hospital

${ }^{7}$ Pamela Youde Nethersole Eastern Hospital

${ }^{8}$ Princess Margaret Hospital

${ }^{9}$ Hong Kong Department of Health

${ }^{10}$ Private practice

February 25, 2022

\begin{abstract}
Objective: To compare the incidences of early and late onset neonatal sepsis, including group B streptococcus (GBS) and Escherichia coli (E.coli) before and after implementation of universal screening. Design: Retrospective cohort study Setting: Eight public hospitals with obstetrics services under the Hospital Authority and 31 Maternal and Child Health Centres (MCHC) under the Department of Health in Hong Kong Population: 460552 women attending routine antenatal service from 2009 to 2020. Methods: Universal culture-based GBS screening was offered to eligible women since 2012. Total maternity, births, GBS screening tests, GBS isolated in maternal genital tract, neonatal sepsis with positive blood or cerebrospinal fluid were retrieved from clinical and laboratory database of the Hospital Authority using clinical data analysis and reporting system (CDARS) and clinical system of MCHCs. Main outcome measures: Maternal GBS colonisation rate, early onset GBS disease, early onset E. coli infection, late onset GBS disease, and late onset E. coli infection Results: Of 318740 women with universal culture-based screening, 63767 women (20.0\%) were screened positive. After implementation of GBS screening, the incidences of both early and late onset neonatal sepsis reduced significantly, including those caused by GBS. There was no change in the incidence of early onset E.coli sepsis, while the incidence of late onset E.coli sepsis reduced. Conclusions: Universal culture-based GBS screening in Hong Kong has been successful in prevention of early and late onset neonatal sepsis, including those caused by GBS. E.coli has become more common than GBS in early neonatal sepsis, although the incidence remained similar.
\end{abstract}

\section{Hosted file}

GBS Final Manuscript BJOG 14022022.docx available at https://authorea.com/users/462365/ articles/557821-incidence-of-early-and-late-onset-group-b-streptococcal-and-escherichia- 
coli-neonatal-infection-after-universal-antenatal-culture-based-screening-of-group-bstreptococcus-in-all-public-hospitals-in-hong-kong-a-retrospective-cohort-study

\section{Hosted file}

GBS table 1.docx available at https://authorea.com/users/462365/articles/557821-incidenceof-early-and-late-onset-group-b-streptococcal-and-escherichia-coli-neonatal-infectionafter-universal-antenatal-culture-based-screening-of-group-b-streptococcus-in-allpublic-hospitals-in-hong-kong-a-retrospective-cohort-study

\section{Hosted file}

GSB Table 2.docx available at https://authorea.com/users/462365/articles/557821-incidenceof-early-and-late-onset-group-b-streptococcal-and-escherichia-coli-neonatal-infectionafter-universal-antenatal-culture-based-screening-of-group-b-streptococcus-in-allpublic-hospitals-in-hong-kong-a-retrospective-cohort-study

\section{Hosted file}

GBS Table 3.docx available at https://authorea.com/users/462365/articles/557821-incidenceof-early-and-late-onset-group-b-streptococcal-and-escherichia-coli-neonatal-infectionafter-universal-antenatal-culture-based-screening-of-group-b-streptococcus-in-allpublic-hospitals-in-hong-kong-a-retrospective-cohort-study 